\title{
Efficiency of the Diesel engine fuelled with the advanced biofuel Bioxdiesel
}

ARTICLE INFO

Received: 19 July 2021

Revised: 29 July 2021

Accepted: 5 August 2021

Available online: 18 August 202
One way to reduce the negative impact of internal combustion engines on the environment is to use advanced biofuels, e.g. Bioxdiesel which is a mixture of Fatty Acid Ethyl Esters (FAEE), bioethanol and standard diesel, with vast majority of the content with biological origin. The FAEE are promising content of the Diesel-Biodiesel-Ethanol blends. The FAEE can be obtained from both vegetable, eg. rapeseed oil and animal fats, as well as waste fats. The article presents research results on the efficiency of a turbocharged Diesel engine equipped with a Common Rail fuel injection system which was powered by Bioxdiesel fuel and for comparison purposes also fed with standard fuel. The effects study showed that even with a lower calorific value of Bioxdiesel fuel when compared to that for the standard diesel, the performance of the engine obtained during the test results was comparable to the standard fuel. Due to the presence of oxygen in the particles of the biofuel, and thus more efficient combustion processes, for a wide range of the minor engine load, the fuel consumption of Bioxdiesel and Diesel fuels was comparable to each other, while at higher engine load the fuel consumption of Bioxdiesel was lower than that for the other fuel.

Key words: Biodiesel, Bioxdiesel, fatty acid ethyl esters, compression ignition engine

This is an open access article under the CC BY license (http://creativecommons.org/licenses/BY/4.0/)

\section{Introduction}

The widespread and ever increasing presence of motor vehicles, construction machines and other self-propelled vehicles have a huge impact on climate change caused by emission of carbon dioxide recognized as one of the main gases responsible for the greenhouse effect.

Intensive research has been carried out on the replacement of fossil fuels, extracted from the interior of the Earth and burnt on the surface with fuel gained from plants cultivated on the surface of the Earth. An intentional cultivation of the energy crops, i.e. oil and starch, is justified, because plants on their growth absorb carbon dioxide in the photosynthesis process $[1,2]$, thus mitigating the presence of the greenhouse gases from the atmosphere.

It is generally estimated that air pollution caused by transport resources reaches above $20 \%$ of the total pollution, and it is even four times higher in large urban areas.

A certain research has been conducted for many years in the field of biofuels but it has been mainly focused on the analysis of possible feeding the Diesel engines with raw vegetable oil for several decades, e.g. Muruyama et al. [3], their esters or mixtures of Diesel fuel with esters or blends of Diesel with alcohol, e.g. Alamu et al. [4]. Conclusions from the above studies showed that a process of supply engines with mixtures of the above-mentioned biocomponents required structural changes in the engine fuel supply systems and combustion organization, as well as a change of logistics processes.

The necessity of introducing structural and logistic modifications to the engine and operational logistics results from different physical-chemical properties of raw vegetable oils, their esters, as well as mixtures in significant proportions with the standard fuel which diesel engines were designed for. The use of biofuels without structural changes in the engine and the combustion organization require a development of fuel with physical characteristics similar to that of a standard fuel. Such fuel is a mixture of ester biocomponents and alcohol with the addition of diesel, called Bioxdiesel.

It should be noted that methyl esters as biocomponents have a lower calorific value by about $10-12 \%$ than the standard fuel. Also methanol used for the production of this biocomponent has a relatively low energy value. The use of ethyl alcohol which has two carbon atoms in its molecule produce an ethyl biocomponent (FAEE) with a higher calorific value than the Fatty Acid Methyl Esters (FAME) methyl biocomponent. The energy value of FAEE is lower than the standard fuel by about $6 \%$.

Works carried out by the authors [8-10] on the replacement of methyl biocomponents with ethyl matched results of works, including [5-7], however, a share of these biocomponents was low, simply an addition to the standard Diesel fuel. Moreover they required modifications to be used in vehicle engines. Therefore, it was decided to develop a composition of biological fuel that did not require changes in a process of the engine operation and combustion organization, with standard diesel oil as an additive. The ethyl components, forming even $75-94 \%$ of the fuel mass for a diesel engine, allow the production of a mixture of hydrocarbons and ethanol with physical properties similar to those of a standard fuel, which does not require modification of the engine design, but only operational changes. Very profitable pro-ecological and energetic properties of higher fatty acid ethyl esters FAEE and in particular a huge potential for their production in Poland, exclusively from vegetable materials and/or waste from animal food production, as well as huge possibilities of bioethanol obtainment, were the basis for works focused on the production of biofuel for diesel engines with a significant proportion of ethyl bio-components, i.e. ethyl esters and ethanol.

A production of alternative fuels from plant and animal wastes is classified as more environmentally advanced biofuels. 
The physicochemical properties of the esters and their application as biodiesel fuel led to standardization of requirements. In Europe (mostly in the European Union) only the FAME are present in the standard, while in the USA, Brazil and India the ester types are not specified, as far as they meet stated requirements. An approach in the European Union is mainly related to the available technology of converting fossil methane into methanol, making the price low in comparison with that for ethanol. There are several advantages of ethanol application which are mainly related to higher calorific value of FAEE in comparison to that for FAME. Ethanol is not as toxic to human organisms as methanol, so special safety precautions have to be met when using and handling methanol. One of the biggest advantages of ethanol is its plant origin which makes fuels made with use of it fully renewable. Additionally planting of the crops used for ethanol production creates less impact on the environment in terms of $\mathrm{CO}_{2}$ emission in comparison with a conversion of methane into methanol.

The energy conversion characteristics and efficiency of engines fueled with the fuel named Bioxdiesel is the scope of research presented in this article.

\section{Bioxdiesel fuel}

The basic components of the Bioxdiesel have biological origin. Fatty Acid Ethyl Esters are the main component used for the fuel preparation. They are obtained on the way of the transesterification reaction of the mixture of:

- Waste animal (pork and poultry) fats

- Waste frying fats

- Vegetable (rapeseed) oil

with anhydrous bioethanol in a presence of potassium hydroxide alkali catalyst. The esterification was performed according to the reaction presented in Fig. 1. This reaction processes were carried out using a semi-technical scale installation.

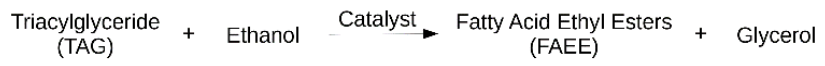

Fig. 1. Reaction of transesterification with ethyl alcohol

It should be emphasized that the physical-chemical and energy properties of FAEE strongly depend on the quality of the raw material, waste origin, climatic conditions for oil (rapeseed) harvesting and processing technology.

Table 1. Average properties of FAEE

\begin{tabular}{|l|c|c|}
\hline \multicolumn{1}{|c|}{ Properties } & Value & Standard \\
\hline Density in $288 \mathrm{~K}\left[\mathrm{~kg} / \mathrm{dm}^{3}\right]$ & 0.876 & EN ISO 3678 \\
\hline Density in $293 \mathrm{~K}\left[\mathrm{~kg} / \mathrm{dm}^{3}\right]$ & 0.873 & EN ISO 3678 \\
\hline Cetane index & 50 & EN ISO 4264 \\
\hline Kinematic viscosity at 313 K & 4,53 & EN ISO 3104 \\
\hline Ignition temperature [K] & 398 & EN 22719 \\
\hline Cloud point temp [K] & 261 & EN 116 \\
\hline Freezing point temp [K] & 249 & EN 116 \\
\hline Cold filter plugging point [K] & 259 & EN 116 \\
\hline Water content [mg/kg] & 50 & EN ISO 12937 \\
\hline Resistance of oxidation [K] & 383 & EN 14112 \\
\hline Acid number $[\mathrm{mg} \mathrm{KOH} / \mathrm{g}]$ & 0.3 & EN 14104 \\
\hline Iodine number & 105 & EN 14111 \\
\hline Content of ethyl esters [\%] & 99.5 & EN 14103 \\
\hline
\end{tabular}

Table 2. Average content of FAEE

\begin{tabular}{|l|c|}
\hline \multicolumn{1}{|c|}{ FAEE contents } & $\% \mathrm{~m} / \mathrm{m}$ \\
\hline Ethyl oleate esters & 87.30 \\
\hline Ethyl ester of hexadecanoin acid & 7.90 \\
\hline Ester cyclopentanon of 2-hydrohydeconin acid & 2.25 \\
\hline Ethyl ester of heptadekain acid & 1.00 \\
\hline Ethyl ester of acetidecanoin acid & 0.50 \\
\hline Ethyl ester of palimitic acid & 0.35 \\
\hline Ethyl ester of stearin acid & 0.48 \\
\hline Total content of odd acids higher fatty acids & 0.22 \\
\hline
\end{tabular}

The Bioxdiesel fuel used for testing is a mixture of FAEE and bioethanol, which are forming $75 \% \mathrm{~m} / \mathrm{m}$ of the content and standard diesel.

Table 3. Selected quality properties of the Bioxdiesel fuel compared with standard Diesel (PN-EN 590) and FAME (PN-EN 14214) requirements

\begin{tabular}{|c|c|c|c|c|c|c|}
\hline \multirow[t]{2}{*}{ Parameter } & \multirow[t]{2}{*}{ Units } & \multirow{2}{*}{$\begin{array}{l}\text { Bioxdiesel } \\
\text { properties }\end{array}$} & \multicolumn{2}{|c|}{$\begin{array}{l}\text { PN-EN } 590 \\
\text { requirement }\end{array}$} & \multicolumn{2}{|c|}{$\begin{array}{c}\text { PN-EN } 14214 \\
\text { requirement }\end{array}$} \\
\hline & & & $\min$ & $\max$ & $\min$ & $\max$ \\
\hline $\begin{array}{l}\text { Cold Filter } \\
\text { Plugging } \\
\text { Point }\end{array}$ & {$\left[{ }^{\circ} \mathrm{C}\right]$} & -17 & \multicolumn{2}{|c|}{$\begin{array}{l}\text { Season de- } \\
\text { pendent eg. } \\
\text { intermediate } \\
\quad-10^{\circ} \mathrm{C}\end{array}$} & \multicolumn{2}{|c|}{$\begin{array}{l}\text { Season depend- } \\
\text { ent eg. inter- } \\
\text { mediate } \\
-10^{\circ} \mathrm{C}\end{array}$} \\
\hline $\begin{array}{l}\text { Cetane } \\
\text { number }\end{array}$ & & 51.9 & 51 & & 51 & \\
\hline $\begin{array}{l}\text { Density at } \\
15^{\circ} \mathrm{C}\end{array}$ & {$\left[\mathrm{kg} / \mathrm{m}^{3}\right]$} & 868 & 820 & 845 & 860 & 900 \\
\hline Flash point & {$\left[{ }^{\circ} \mathrm{C}\right]$} & 24 & 55 & & 101 & \\
\hline $\begin{array}{l}\text { Viscosity at } \\
40^{\circ} \mathrm{C}\end{array}$ & {$\left[\mathrm{mm}^{2} / \mathrm{s}\right]$} & 2.33 & 2 & 4.5 & 3.5 & 5 \\
\hline $\begin{array}{l}\text { Calorific } \\
\text { value }\end{array}$ & {$[\mathrm{MJ} / \mathrm{kg}]$} & 38.5 & \multicolumn{2}{|c|}{42.8} & \multicolumn{2}{|c|}{38} \\
\hline
\end{tabular}

Table 4. Average content of bioethanol

\begin{tabular}{|l|c|}
\hline Alcohol proof in 293K in [\%] vol. & $99.8-99.9$ \\
\hline $\begin{array}{l}\text { Carbonyl compound content in terms } \\
\text { of acetaldehyde, [g/l] spirit } 100 \%\end{array}$ & $0.09-0.2$ \\
\hline $\begin{array}{l}\text { Fusels content in terms of amyl, propanol, butanol } \\
\text { alcohol mixture [g/l] spirit } 100 \%\end{array}$ & $2.0-3.2$ \\
\hline Methyl alcohol content in [g/100 ml] spirit 100\% & $0.01-0.03$ \\
\hline $\begin{array}{l}\text { Acid content in terms of acetic acid, [g/l] spirit } 100 \% \\
\text { (after gasification) }\end{array}$ & $0.006-0.01$ \\
\hline $\begin{array}{l}\text { Acid content in terms of acetic acid, [g/l] spirit } 100 \% \\
\text { (before gasification) }\end{array}$ & $0.2-0.3$ \\
\hline Water concentration, [\%] mass & $0.057-0.18$ \\
\hline Residue of evaporation, [g/l] spirit $100 \%$ & $0.003-0.005$ \\
\hline
\end{tabular}

Analysis of Bioxdiesel properties presented in Table 3 shows that the fuel meets the requirement set for diesel, except for the flash point which has only a logistic importance.

Bioxdiesel is characterized by better lubricity properties than those for diesel, measured with both HFRR and SL BOCLE methods, meeting lubrification standards provided for the U.S. and Europe which contributes positively to the sustainability and reliability of engines [10]. 
Table 5. Comparison of lubricity of tested biofuel and standard diesel

\begin{tabular}{|l|c|c|}
\hline $\begin{array}{l}\text { Lubricity measure- } \\
\text { ment }\end{array}$ & Bioxdiesel & $\begin{array}{c}\text { Diesel (standard re- } \\
\text { quirement) }\end{array}$ \\
\hline $\begin{array}{l}\text { HFRR } \\
\text { EN ISO 12156-1 }\end{array}$ & 195 & $<460$ \\
\hline $\begin{array}{l}\text { SL BOCLE } \\
\text { ASTM D 6078-97 }\end{array}$ & 4750 & $>2800$ \\
\hline
\end{tabular}

Bioxdiesel fuel has also significantly better properties at low temperatures which is important on a winter operation.

A temperature range of evaporation of individual fuel fractions is a very important property in view of an evaporation itself, of the preparation of the combustible mixture, the nature and time as well as the quality of the combustion process. The main differences of Bioxdiesel and diesel are presented on boiling curves in Fig. 2. This figure also shows the boiling curves for ethyl ester and crude rapeseed oil. The graph shows that the standard fuel has a boiling range in the range of $180-360^{\circ} \mathrm{C}$; vegetable fuels (rapeseed oil and FAEE) have a narrow boiling range (approx. $50^{\circ} \mathrm{C}$ ), while Bioxdiesel has a wide range of the evaporation range, about $280^{\circ} \mathrm{C}\left(80-360^{\circ} \mathrm{C}\right)$.

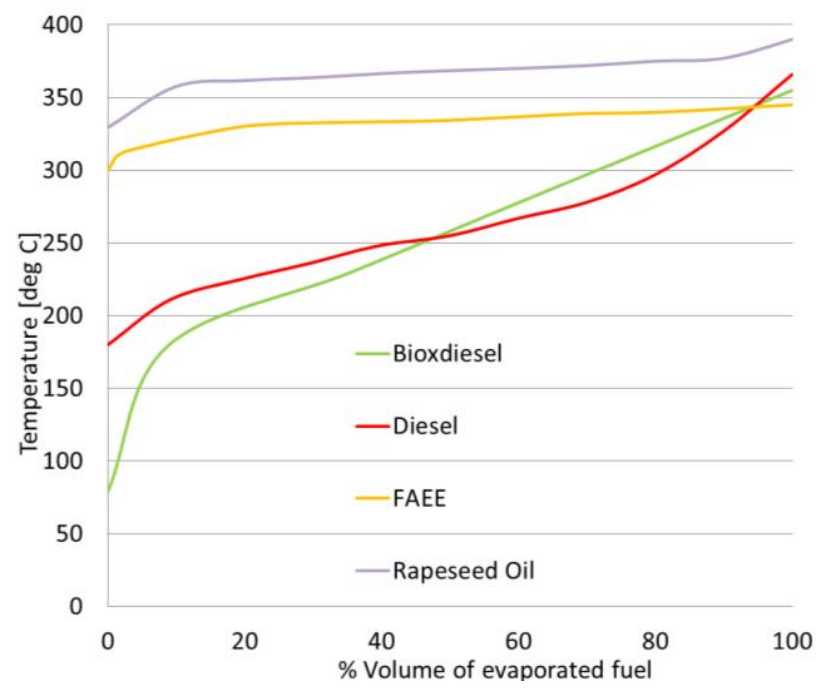

Fig. 2. Evaporation curves for Diesel, FAEE, raw rapeseed oil and Bioxdiesel

It should be expected that the very favourable fractional composition of Bioxdiesel fuel has a positive effect directly on the engine start-up process, as well as all phases of the process of preparation and combustion of this fuel, both in stationary and especially in non-stationary states.

\section{Research procedures}

The efficiency of Diesel engine fueled with experimental Bioxdiesel was compared to the effects of a standard diesel supply using a stationary test stand based on the New European Driving Cycle (NEDC) procedure.

The measurement was performed according to the testing procedure which was prepared based on the NEDC testing procedure. Table 7 contains measurement points (according to NEDC procedure). Points marked with an asterisk ' $*$ ' are corresponding to the situation when the vehicle travels with a constant speed and these points cover most of the test (see Fig. 3). The engine efficiency was measured in each of the 20 testing points.

There were also performed tests with constant engine speed and variable load. The tests were performed at 1500 , 2500 and $3500 \mathrm{rpm}$. The load varied from 5 to $160 \mathrm{Nm}$. The engine speed and the load ranges used in the tests correspond to those most frequently used in everyday operation of the vehicles.

The engine was tested with fossil Diesel and Bioxdiesel fuels.

For testing purposes the 1.3 litre displacement, turbocharged Diesel engine was used. The engine description is presented in Table 6. The engine was coupled with the Schenk electro-eddy brake.

Table 6. Description of engine used for testing

\begin{tabular}{|l|c|}
\hline Engine type & Compression ignition \\
\hline No of cylinders & 4/inline \\
\hline Valves & DOHC/4 valves per cylinder \\
\hline Bore & $69.6 \mathrm{~mm}$ \\
\hline Piston stroke & $82 \mathrm{~mm}$ \\
\hline Injection & Common rail \\
\hline Exhaust gases recirculation & with EGR valve \\
\hline Engine displacement & $1248 \mathrm{ccm}$ \\
\hline Compression ratio & 18 \\
\hline Max output power & $51 \mathrm{~kW} @ 4000 \mathrm{rpm}$ \\
\hline Max output torque & $180 \mathrm{Nm} @ 1750 \mathrm{rpm}$ \\
\hline
\end{tabular}

The engine fuel dosing was measured with Dynamic Fuel Meter AVL 733 S.

The engine efficiency measurement was performed according to the procedure based on the NEDC test. The NEDC is a testing methodology which represents operation of the vehicle in real life operation. During the test, the

Table 7. Measurement points according to EUDC testing procedure

\begin{tabular}{|c|c|c|c|}
\hline ID & $\begin{array}{l}\text { Engine } \\
{[\mathrm{rpm}]}\end{array}$ & $\begin{array}{l}\text { Engine torque } \\
{[\mathrm{Nm}]}\end{array}$ & $\begin{array}{l}\text { Estimated vehicle speed } \\
{[\mathrm{km} / \mathrm{h} / \text { gea }] \mathrm{r}}\end{array}$ \\
\hline 1 & 820 & 45 & \\
\hline 2 & 850 & 20 & \\
\hline 3 & 1050 & 15 & \\
\hline 4 & 1250 & 20 & \\
\hline 5 & 1400 & 40 & \\
\hline 6* & 1550 & 4 & 35/III \\
\hline $7 *$ & 1590 & 10 & 50/IV \\
\hline 8 & 1650 & 37 & \\
\hline 9* & 1730 & 11 & $70 / V$ \\
\hline 10 & 1740 & 26 & \\
\hline 11 & 1800 & 38 & \\
\hline $12 *$ & 1920 & 3 & $15 / I$ \\
\hline 13 & 2050 & 26 & \\
\hline $14 *$ & 2200 & 4 & $50 /$ III \\
\hline $15 *$ & 2260 & 4 & 32/II \\
\hline 16 & 2400 & 55 & \\
\hline $17 *$ & 2500 & 34 & $100 / \mathrm{V}$ \\
\hline 18 & 2700 & 73 & \\
\hline 19 & 2930 & 80 & \\
\hline $20 *$ & 3020 & 55 & $120 / V$ \\
\hline
\end{tabular}


engine was tested at 20 points which represented a driving cycle with different speeds and loads. Points 6, 7, 9, 12, 14, 15,17 and 20 were corresponding to the phases of the NEDC test, when the vehicle run with a constant speed (see Fig. 3).

In addition to the NEDC testing points, the engine performance was measured at 1500, 2500 and $3500 \mathrm{rpm}$, with a variable load 5 to $160 \mathrm{Nm}$.

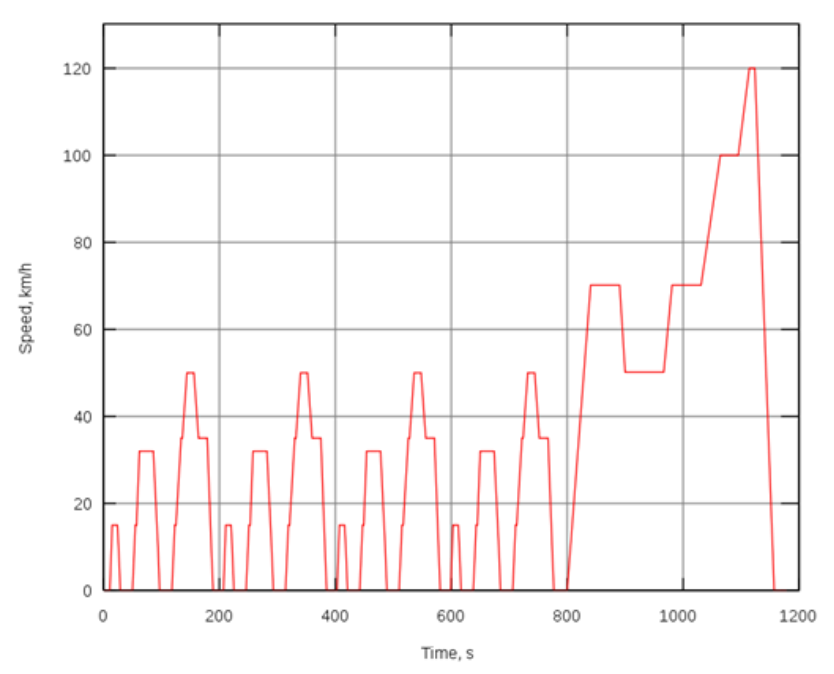

Fig. 3. Graphical representation of the NEDC testing procedure

The engine was tested with two fuels: an advanced, experimental Bioxdiesel fuel and a standard Diesel. red:

During the tests the following parameters were measu-

- Fuel dose per cycle (volume),

- Fuel consumption (mass),

- Engine efficiency,

- Exhaust gases recirculation ratio EGR,

- Emission of exhaust gases (CO and HC).

Figure 4 presents a comparison of the volume of fuel doses per cycle during feeding the engine with Bioxdiesel and standard Diesel fuels. One can notice that the dose sizes are similar for both fuels. For the measurement points with a smaller engine speed and load, the dose sizes are smaller for standard Diesel and the testing points with higher load fuel dose sizes are smaller for Bioxdiesel fuel.

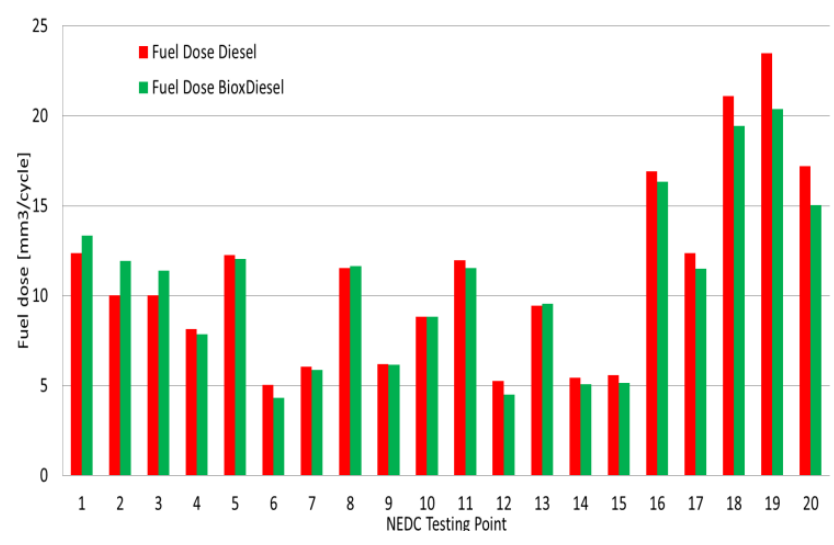

Fig. 4. Comparison of the fuel dose for the engine fed with Bioxdiesel and Diesel fuel for selected operation points according to NEDC procedure
Figure 5 presents a comparison of mass fuel consumption of the engine fed with standard and Bioxdiesel fuels. Again, the fuel consumption for the testing points with low loads are comparable for both fuels and at the testing points, with higher values of load (points 18, 19 and 20), the fuel consumption is smaller for Bioxdiesel.

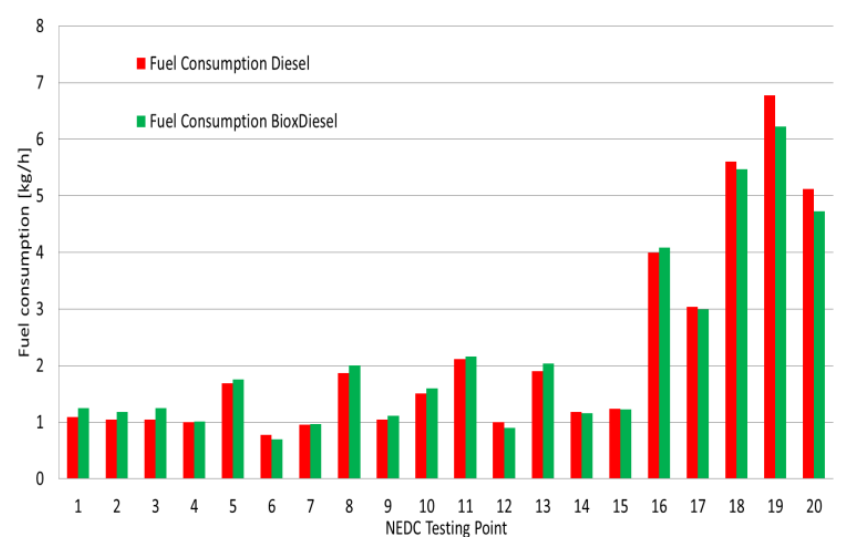

Fig. 5. Comparison of the fuel consumption for the engine fed with Bioxdiesel and Diesel fuel for selected operation points according to NEDC procedure

Figure 6 presents comparison an overall engine efficiency for the engine fed with both fuels. The engine efficiency for feeding with Bioxdiesel fuel is significantly higher. Higher values of the overall efficiency of the Bioxdiesel fueled engine result from the improved oxidation of energy components (HC) due to the oxygen content in the fuel mixture particles. Concentration of unburnt hydrocarbons (HC) in exhaust gases are presented in Fig. 7 and concentration of carbon monodioxide (CO) in exhaust gases is presented in Fig. 8.

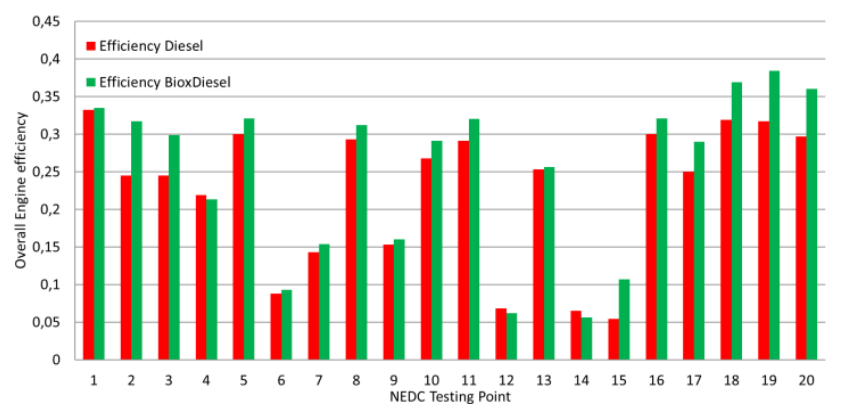

Fig. 6. Comparison of the overall engine efficiency for the engine fed with Bioxdiesel and Diesel fuel for selected operation points according to NEDC procedure

This is particularly important at non-stationary states of the engine operation.

The confirmation of the fact that the Bioxdiesel fuel combustion process is better when compared to that for Diesel, and thus directly affecting engine efficiency, is shown in significantly lower values of unburnt hydrocarbons (HC) and carbon monoxide (CO) emissions presented in Figs 7 and 8. Despite that the calorific value of Bioxdiesel is $10 \%$ lower than that of the standard fuel, the engine performance and fuel consumption are comparable for both fuels, however in some cases they are better for the fuel 


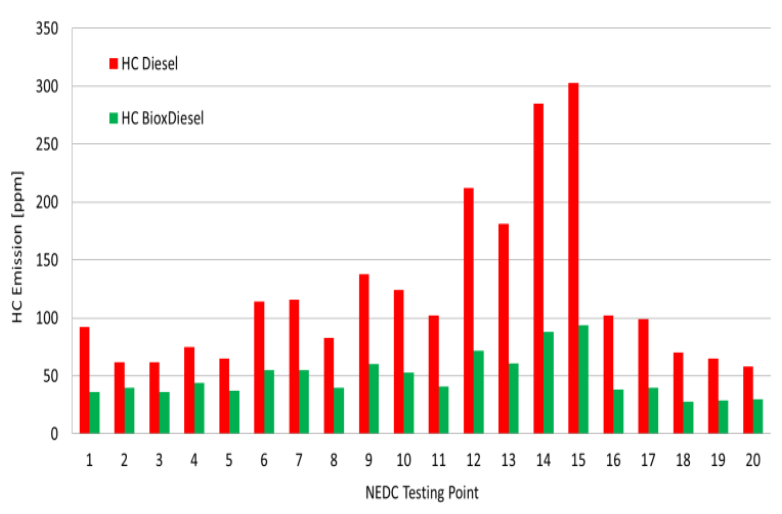

Fig. 7. Emission of unburnt hydrocarbons $(\mathrm{HC})$ from the engine fed with Bioxdiesel and Diesel fuels
$2500 \mathrm{rpm}$
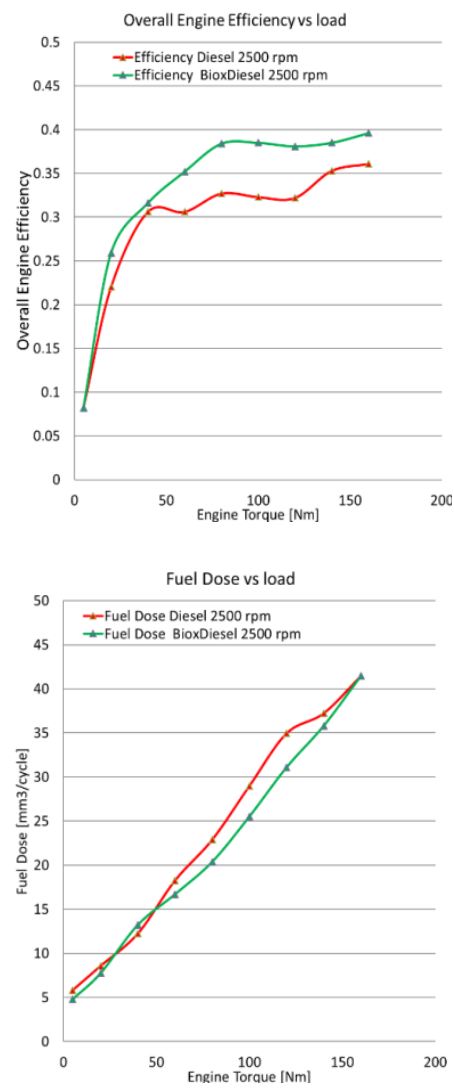

Fuel Consumption vs load

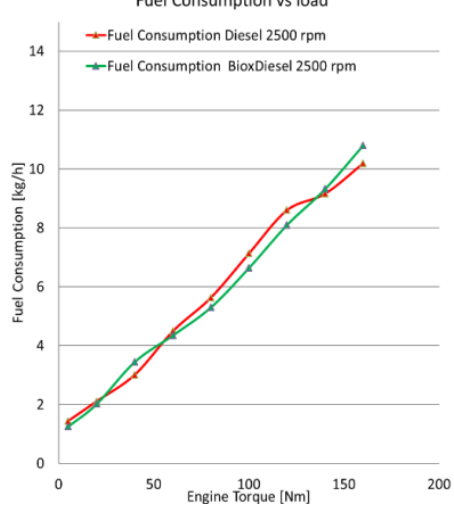

$3500 \mathrm{rpm}$

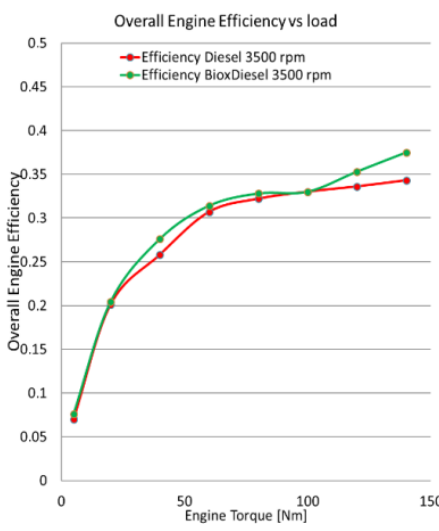

Fuel Dose vs load

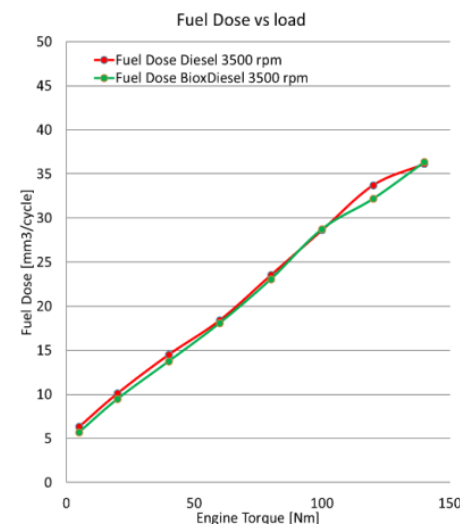

Fuel Consumption vs load

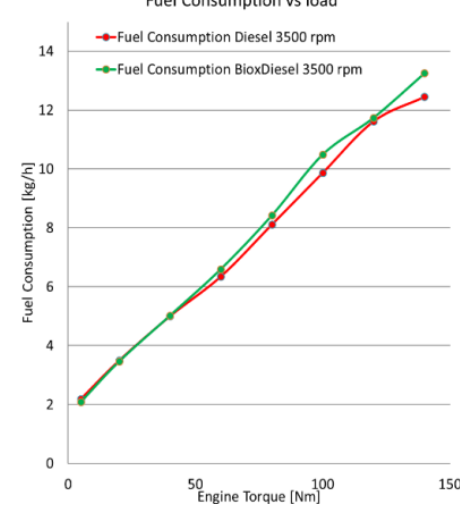

Fig. 9. Comparison of overall engine efficiency, fuel doses per cycle and engine fuel consumption at 1500, 2500, $3500 \mathrm{rpm}$ in variable load of the engine fed with Bioxdiesel and Diesel 

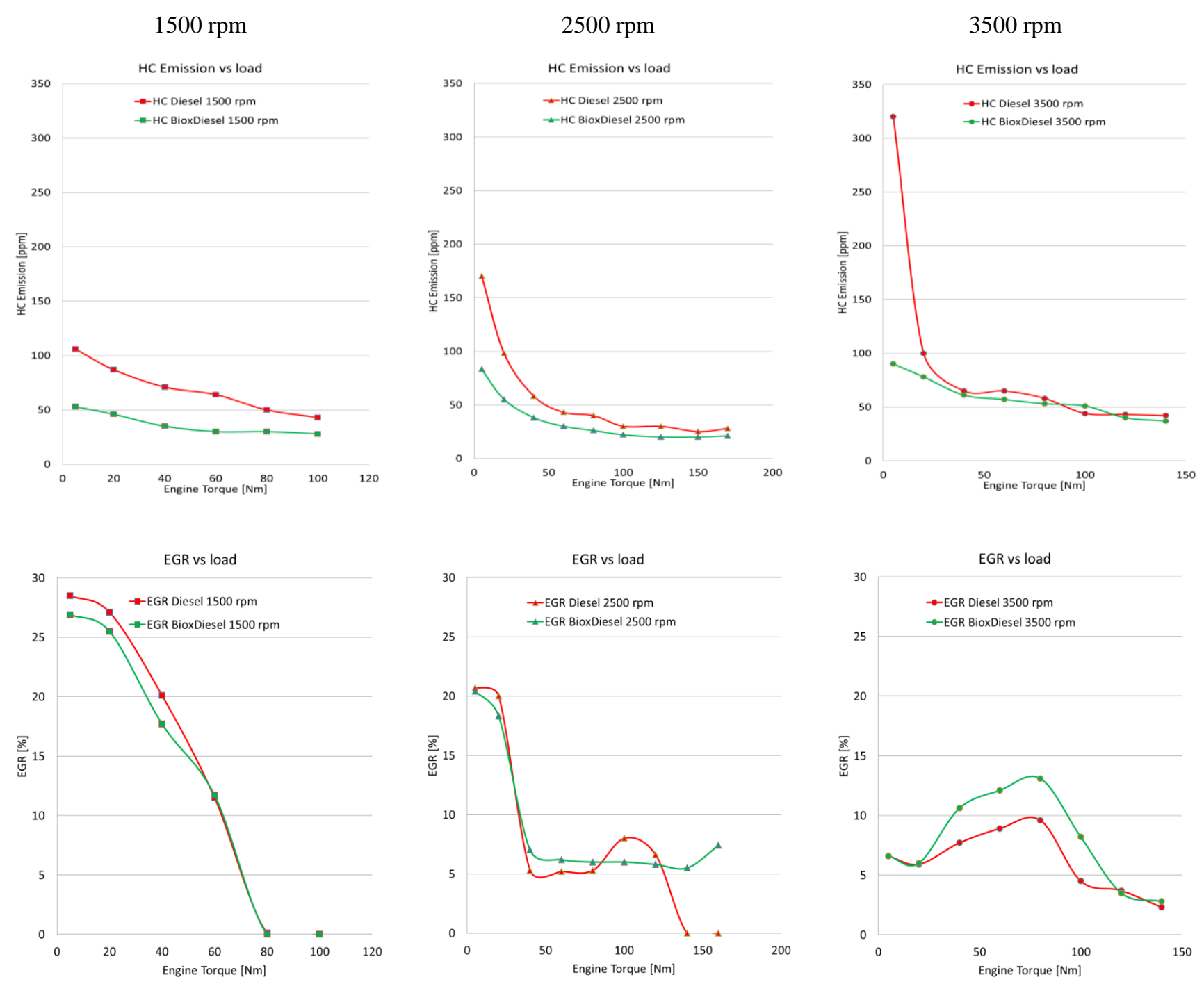

Fig. 10. Comparison of unburned hydrocarbons (HC) emission and degree of exhaust gases recirculation at 1500, 2500, $3500 \mathrm{rpm}$ in variable load of the engine fed with Bioxdiesel and Diesel

which contains renewable components. Higher values of the overall efficiency of the engine when fuelled with Bioxdiesel fuel result from the structure of FAEE and ethanol molecules containing oxygen atoms, as well as a faster evaporation process of light fractions (ethanol) of Bioxdiesel fuel, affecting the rate of a heat generation as well as a better combustion process (in terms of the complete combustion) of fuel energy particles.

Figures 9 and 10 present a comparison of basic values characterizing a fuel supply, the engine efficiency, emission of unburnt components and a degree of the exhaust gases recirculation from both the engine fed with Bioxdiesel and standard diesel.

For a wide range of engine speeds (1500, 2500 and $3500 \mathrm{rpm}$ ) the fuel consumption dependence on the engine load is comparable for both fuels. For the medium engine speed and load in the range from 50 to $140 \mathrm{Nm}$ it is noticeable that the fuel consumption and the fuel dose are smaller for Bioxdiesel fuel.

In general, the engine efficiency is better for Bioxdiesel fuel for a wide range of the tested engine speeds. There are noticeable differences in the overall engine efficiency va- lues at individual measurement points, especially at 2500 rpm.

Significant differences in efficiency result from the differences in the physical and chemical properties of both fuels. The better physical properties of Bioxdiesel fuel associated with the fractional composition (see Fig. 2) lead directly to a better process of evaporation of some Bioxdiesel fuel in relation to diesel fuel and higher combustion efficiency. On the other hand, more favourable chemical properties enable a better combustion process due to the oxygen contained in ethanol and FAEE molecules.

The unequivocal interpretation of the differences in the efficiency of burning both fuels, especially at $2500 \mathrm{rpm}$ requires additional in-depth studies of possible effects of individual carbon and hydrogen atoms, as well as oxygen separately contained in the structure of FAEE (made from waste vegetable and animal fats) and ethanol. However, these further studies which may bring a lot of important information on the physical and chemical characteristics of the organization of the combustion process in the engine cylinders fed with Bioxdiesel multi-component fuel go beyond the scope of this work. 
A slightly lower increase in the engine efficiency fed with Bioxdiesel at engine speed $3500 \mathrm{rpm}$ in the medium load range can be caused by significantly higher exhaust gas recirculation (Fig. 10).

Exhaust gas recirculation curves presented on engine load characteristics (Fig. 10) show that no significant differences in exhaust gas recirculation values at individual measuring points were observed. After considering the method of controlling an amount of air by regulating exhaust gas recirculation the results obtained at the rotational speed of $3500 \mathrm{rpm}$ can be explained as the control system correction.

It is also worth noting here that the road tests carried out by the authors using Bioxdiesel $[8,9]$ showed analogous operating properties of engines as those for diesel oil supply with a softer operation and a lower level of sound emission. However, these observations do not concern a subject of this article.

\section{Conclusions}

A modelling of physical and energetic properties of the standard Diesel fuel is also possible by means of ethanol esterification of waste animal and vegetable fats, forming FAEE mixed with ethanol and the addition of standard fuel.

The biocomponent structure of Bioxdiesel fuel enables a much earlier start of the evaporation process of this fuel due to the alcohol content which is characterized by a relatively low evaporation temperature, and thus a better process of preparation of the combustible mixture and combustion of fuel when compared to those for the standard fuel supply. Bioxdiesel fuel won a distinction of higher engine efficiency.

The content of oxygen bound in FAEE biocomponent particles and ethanol enables a better combustion of hydrocarbons contained in Bioxdiesel fuel in relation to the quality of the combustion process of a standard fuel which also results in greater efficiency of the Bioxdiesel fuelled engine when compared to that for a standard fuel powered engine.

The results of the experimental studies show that even though a character of the impact of individual Bioxdiesel fuel components on its combustion efficiency has not been clearly defined yet, Bioxdiesel consisting of $75 \%$ renewable components with FAEE (made from waste animal and vegetable fats) and bioethanol could be an alternative fuel for Diesel engines in the efficiency aspect.

\section{Nomenclature}

FAME Fatty Acid Methy Ester

FAEE Fatty Acid Ethyl Ester

$\mathrm{NO}_{\mathrm{x}} \quad$ Nitrogen oxides
EGR Exhaust Gas Recirculation

NEDC New European Driving Cycle

\section{Bibliography}

[1] DEMIRBAS, A. Biomass resource and biomass conversion processing for fuels and chemicals. Energy Conversion and Management. 2001, 42(11), 1357-1378.

https://doi.org/10.1016/S0196-8904(00)00137-0

[2] REIJNDERS, L. Conditions for the sustainability of biomass based fuel use. Energy Policy. 2006, 34(7), 863-876. https://doi.org/10.1016/j.enpol.2004.09.001

[3] MURUYAMA, T., OH, Y., MIYAMOTO, N. et al. Low carbon flower buildup, low smoke, and efficient diesel operation with vegetable oils by conversion to mono-esters and blending with diesel oil or alcohols. SAE Transactions. 1984, 93, 292-302. http://www.jstor.org/stable/44721476

[4] ALAMU, O.J., WAHEED, M.A., JEKAYINFA, S.O. Effect of ethanol-palm kernel oil ratio on alkali-catalized biodiesel yield. Fuel. 2008, 87(8-9), 1529-1533. https://doi.org/10.1016/j.fuel.2007.08.011

[5] BALA, B.K. Studies on biodiesels from transformation of vegetable oils for diesel engines. Energy Education Science Technology. 2005, 15, 1-43.

[6] ZHANG, Y., DUBE, M.A., MCLEAN, D.D. et al. Biodiesel production from waste cooking oil: 2. Economic assessment

Prof. Mieczysław Struś, DSc., DEng. - Faculty of Mechanical and Power Engineering, Wrocław University of Science and Technology.

e-mail: mieczyslaw.strus@pwr.edu.pl

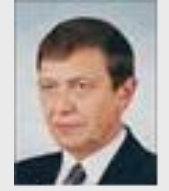

and sensitivity analysis. Bioresource Technology. 2003, 90(3), 229-240. https://doi.org/10.1016/S0960-8524(03)00150-0

[7] LIMA, J.R.d.O., da SILVA, R.B., de MOURA, E.M. et al. Biodiesel of tucum oil, synthesized by methanolic and ethanolic routes. Fuel. 2008, 87(8-9), 1718-1723. https://doi.org/10.1016/j.fuel.2007.09.007

[8] STRUŚ, M., POPRAWSKI, W., REWOLTE, M. Testing the fleet of the vehicles with diesel engines fed by BIOXDIESEL fuel. Combustion Engines. 2017, 170(3), 37-41.

https://doi.org/10.19206/CE-2017-306

[9] STRUŚ, M., POPRAWSKI, W., REWOLTE, M. et al. Feeding the engines of fleet vehicles with Bioxdiesel fuel and heavy alcohols. Journal of KONES Powertrain and Transport. 2016, 23(4), 495-504.

https://doi.org/10.5604/12314005.1217291

[10] STRUŚ, M. Assessment of the impact biofuels on selected exploitation properties of diesel engines (in Polish). Publishing House of the Wroclaw University of Technology. 2012. https://www.dbc.wroc.pl/Content/19614/PDF/strus_ocena_wp lywu.pdf

Wojciech Poprawski, DEng. - Faculty of Mechanical and Power Engineering, Wrocław University of Science and Technology.

e-mail: wojciech.poprawski@pwr.edu.pl 